
consideration all volcanic action involving the exten- ble, has been to demonstrate conclusively to workers
sive eruption of lavas, whether dry or saturated with with many other salts. As uforesaid, how-
in metals the fact of the liability of the materials they water. They also exclude the maar process (single explosion) as an explanation of medium and large craters, canic theory, as a whole, is therefore rejected. but a th limited use may be found for the maar phase of vol enough for all the phenomena.

$$
\text { (To be continued.) }
$$

GAS ANALYSIS BY SOUND.

A NOVEL method of analyzing mixtures of two gases of different densities has been brought under the notice
of the French Academy of Sciences by $\mathbf{M}$. Hardy. It depends upon the application of sound vibrations; and because it is primarily designed for the purpose of determining the proportion of formene, or fire damp, in the air of coal mines. This appliance consists of two
organ pipes, of exactly the same dimensions, and giv. organ pipes, of exactly the same dimensions, and giv-
ing out the same note when blown with air under ornormal air and the other of these pipes is flled with per cent. of marsh gas, and the pipes are then sounded, the unison is disturbed, and one beat is heard every
three seconds. With 2 per cent. of marsh gas in the three seconds. With 2 per cent. of marsh gas in the
air. there are three beats in two seconds; with 3 per may be obtained when carbonic acid gas is the added may be obtained when carbonic acid gas is the added with organ pipes sounding $\mathrm{C}_{4}$. For mixtures having a with organ pipes sounding C. For mixtures having a
density closely approach ing that of air, pipes sounding $C_{6}$ are more suitable. Each determination is the
work of a few seconds; and the inventor believes the work of a few seconds; and the inventor believes the
apparatus to be of great practical value for the analysis of suspected air taken from mines or other inclosed spaces. It is interesting to note, in connection with M. Hardy's method is based is a well-known concomitwhere the air is liable to marked carbonic acid pollu tion through lack of proper ventilation. At the close
of a crowded assemblage in such places the organ pipes give quite a different pitch of sound from that pipes give quite a differen
with which they began.

\section{PROPERTIES OF DIAMONDS.}

Morssan has given the results of an investigation to
determine the temperature at which diamonds begin to burn in oxygen, these temperatures being measured by means of a thermoelectric couple. As the tempera ture is slowly raised. the combustion takes place slowly and without the production of light, the only evidence of it being the effect produced ${ }^{\circ}$ y the issuing gas on and a distinct flame is visible. The eight different specimens examined gave results as follows : Yellowish-brown carbonado burned at $690^{\circ}$ with flame ; black carbonado at $710^{\circ}-720^{\circ}$ with flame; transparent Brazilfrom the Cape at $780^{\circ}-790^{\circ}$ without a flame ; Brazilian hort at $790^{\circ}$ without a flame and at $840^{\circ}$ with a flame. Cape bort at $790^{\circ}$ without a flame and at $840^{\circ}$ with a flame ; rery hard bort at $800^{\circ}$ without and at $875^{\circ}$ with a
flame. The harder the diamond, as a rule, the higher its flame. The harder the diamond, as a rule, the higher its dianonds do not lose weight, though they may lose this temperature dry chlorine and dry hydrogen fluoride have no action on them. The vapor of sulphur attacks them only at $1,000^{\circ}$; but with carbonado, car-
bon disulphide is produced at $900^{\circ}$. The vapor of sodium has no action at $600^{\circ}$. Iron at its fusing point attacks the diamond readily and graphite separates on hioh temperature the diamond is rapidly dissolved with evolution of carbon monoxide but no hydrogen. \section{UNIVERSAL POLYMERISM OR POLY-
STERISM.}

By Henry Wurtz, Ph.I.

ALL intelligent metal - workers know that metals vary in their qualities according to the special treat-
ment and handling they receive. The same principle, as can be proved, applies to all bodies whatever, both solid and priquid.

Chemists have in very recent yearsbegun to give some attention to these internal transformations through external causes. Sterry Hunt, Walthere Spring, of Liege, and the eminent metallurgist Roberts-A usten may be writer wrote of it as long ago as 1875 , in a be found. in abstract, in the Am. Chemist, March, 1876. Being during that year in continual association with Sterry Hunt, at the Philadelphia Exposition-both being members
of the international groups of judges, we discussed of the international groups of judges, we discussed
these things extensively, and Hunt has approximated in some of his later writings to the views of the present books published by him just hefore his lamented death,
such as his "New Basis for Chemistry, and others, he has made it the main foundation of his theories. Before 1876 he seemed to the writer to share the usual
view of chemists and mineralogists, that each distinct view of chemists and mineralogists, that each distinct chemical element and compound should possess a dis-
that the variations of the flgures obtained by different experimenters were due to impurities, errors of manipu-
lation, differences of temperature, and other incidents more or less vaguely assumed. As to errors, this notion is wholly inadmissible. For chemists, the names
given below will suffee to disprove this. With due given below will suffice to disprove this. With due
skill and care-without which these men never worked -there is no difficulty in obtaining, with the same material, density figures agreeing even to the third place of decinals, or certainly to half the second place, and more especially with heavy metals. And chemists of this class never, or very rarely, work on any but chemi-
cally pure bodies.
The main object of the writer in preparing this tawork with to these variations in of the maty, and thus lead ever, it is but very recently, but little before this presto introduction into their minds of novel ideas on this
subject. It may lead some practical men to study for all atracted to this aubject: and there are still
many who retain the ancient faith in the supposed subject. It may lead some practical men to study for
themselves the modes of producing such variations at will, accompanied, as they must be, by corresponding $\begin{aligned} & \text { accidental causes of variability of determinations of } \\ & \text { density of both elements and compounds, and in the }\end{aligned}$ will, accompanied, as they must be, by corresponding density of both elements and compounds, and in the
variations in all the other qualities of the metal. It
should be repeated that this is a brunch of chemistry mitted " "polymery, pure of enemical body, or every ad-
ingacteristic and invariawhich the writer believes to be as universal, as funda- ble density.
Eental and as important as an y other whatever, and
Evidence has been also introduced into this table which has been hitherto unappreciated, and therefore to show that the true principle of universal "polygnored and neglected, almost universally by chemists. Inerism" is quite as marked in liquid as in solid bod It would have been interesting to add to this table, ies, so that it is not due to a mere change of mechanwere it not probably too long already, some of the ical structure. Organic bodies, of both liquid and
commoner chemical compounds, such as occur, for ex- solid forms, show it quite as plainly. Some gaseous mple, as pure crystallized substances obtained from and vaporous bodies probably show it also. But these olutions and otherwise, and which also show varia- must constitute future subjects. ions, sometimes even to a greater extent than the "Polymerism" is a vague and wholly unsatisfactory metals. This was probably for the flrst time pointed out term. It merely means "of many parts." The writer
in 1852 by the German chemist Kremers, who proved, desires to displace it by the term polysterism, which 1852 by the German chemist Kremers, who proved, desires to displace it by the term pol ysterism, which
means "of many volumes." This has a direct meanGlauber's salt). when crystallized at $158^{\circ} \mathrm{F}$.. showed ing and a direct application to this universal chemiOthe density 2654 , but when at $212^{\circ} \mathrm{F}$., showed $2 \cdot 684$.
cal law. There are, moreover, several kinds of poly-
Otheres; but this cannot be made clear till after the as high as 2.73. Some years later, two French chem- issue of some yet unpublished investigations of the as high as $2 \cdot 73$. Some years later, two French chem- issue
ists, Favre and Valson, obtained similar and larger 1 writer.

TABLE

the minimum and maximum densities of the best-known elernents of matter; by Henry Wurtz, Ph. D

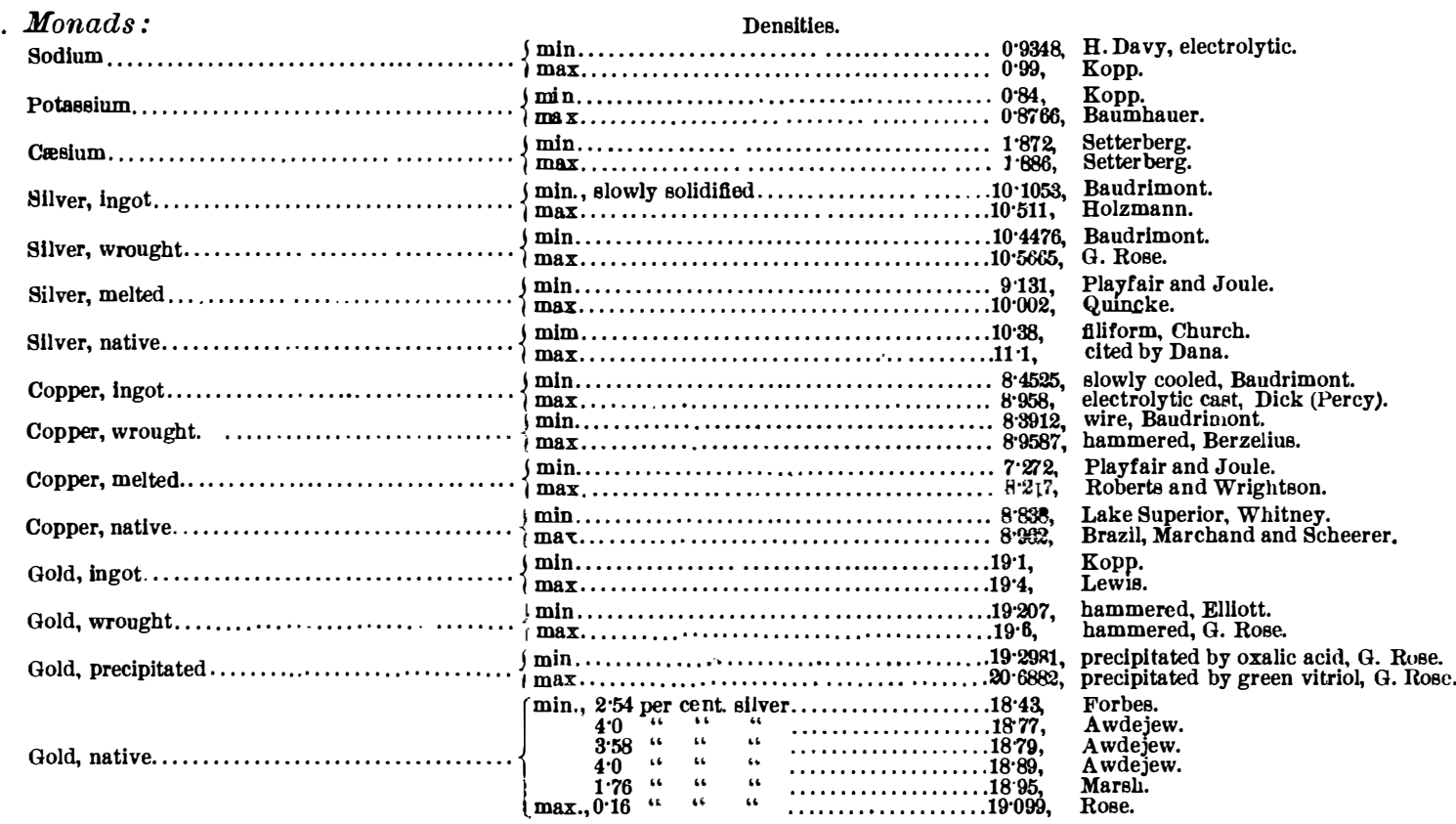

It will be readily observed that the variations in gold bear no relation to the small proportions of silver the native gold.

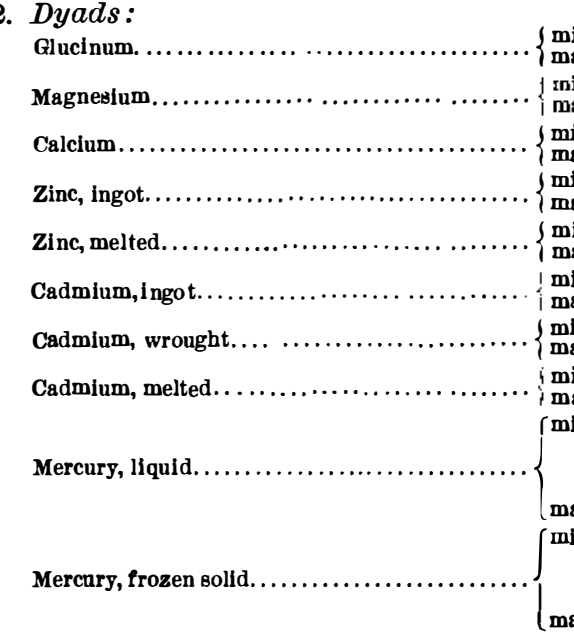

\section{Triads:}
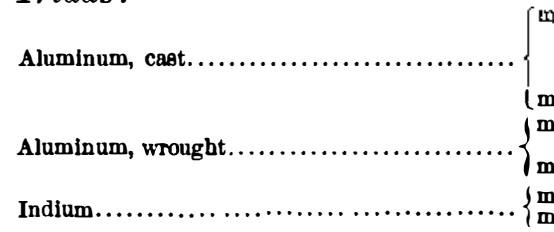

Thallium, wire..............................

\section{Tetrads :}

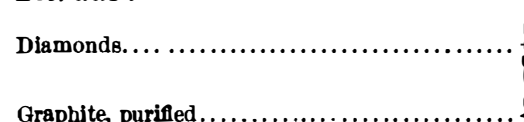

Retort-carbon............................ $\{\mathrm{m}$
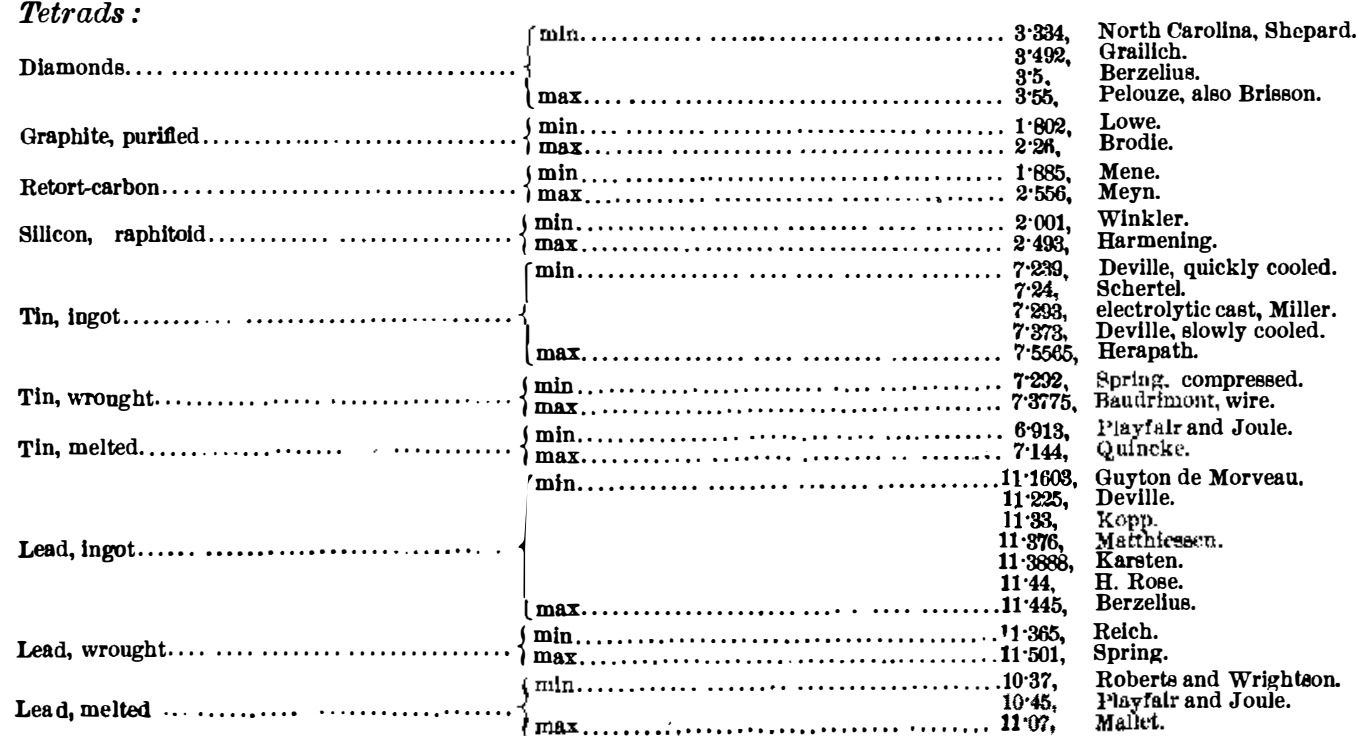
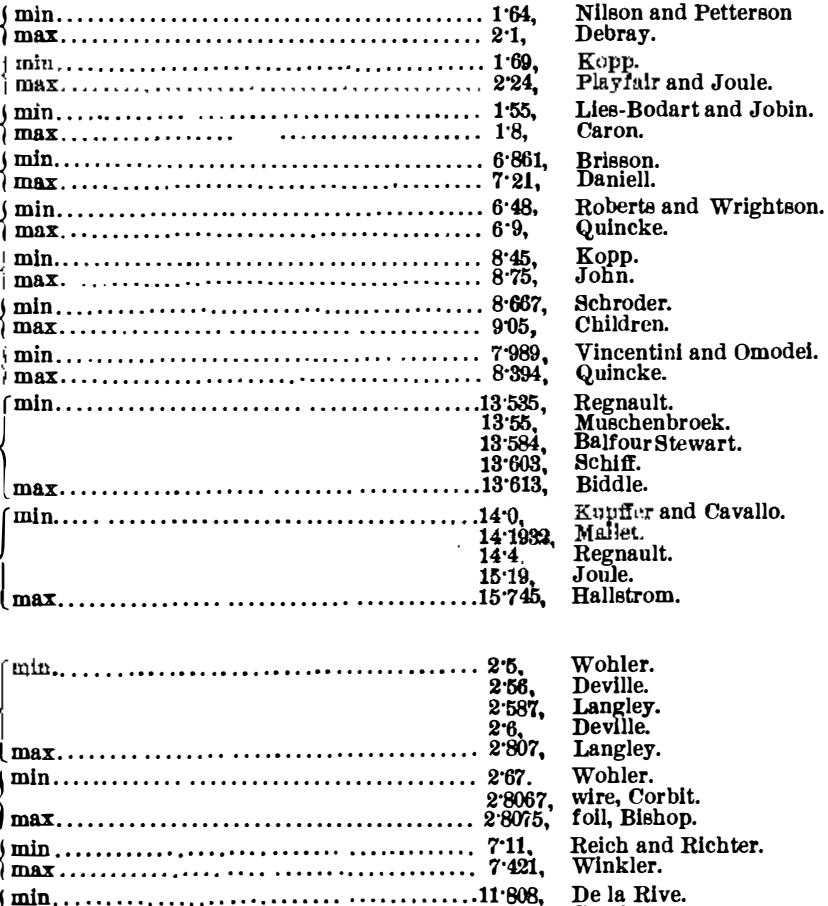


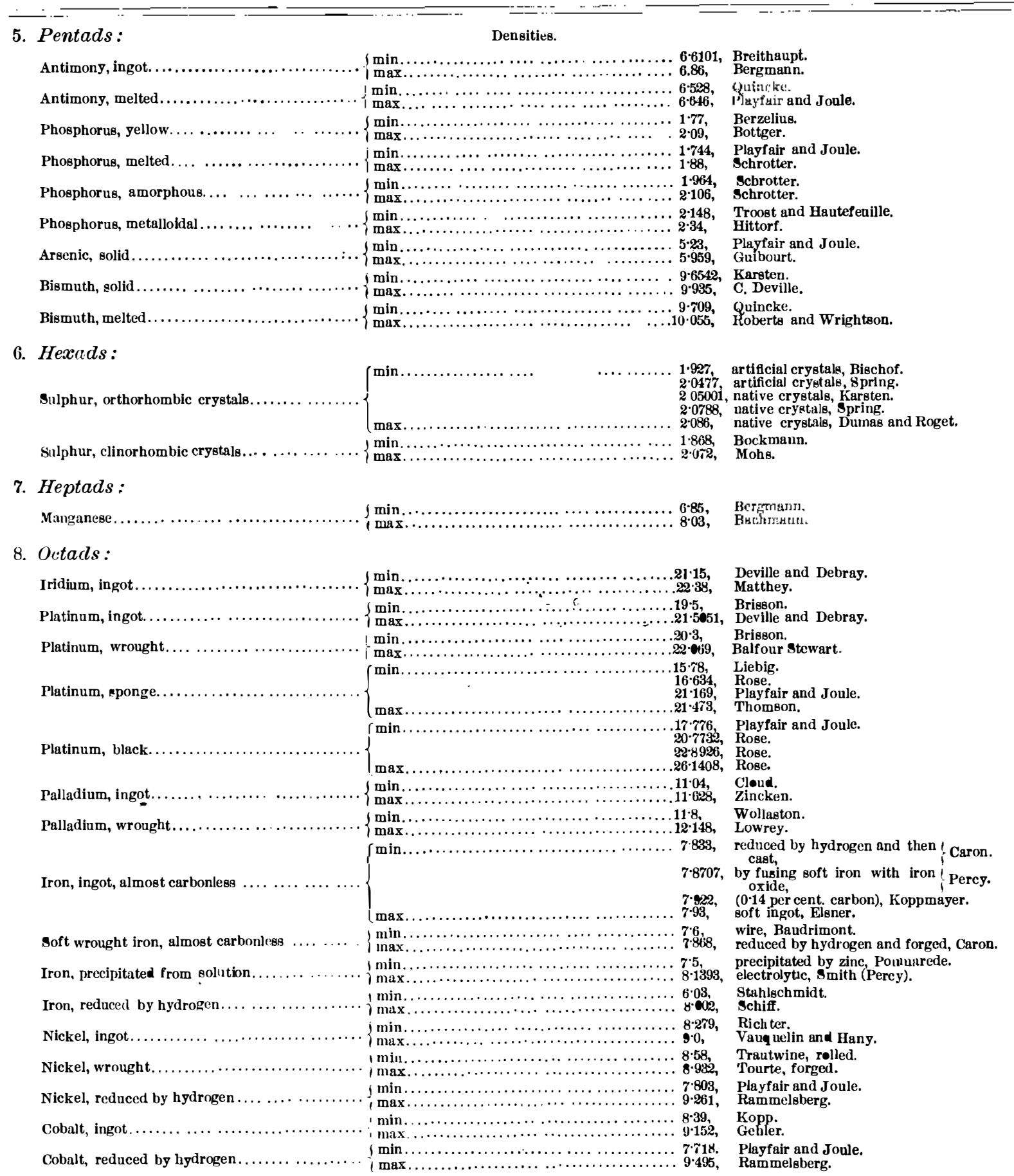

It is proper for me to acknowledge my indebtedness alone, this one observation would be sufficient to induce or a large proportion of the above figures to the magSuch figures have been carefully culled from this and from some other sources as would bring out most sharply the principles to be illustrated.

ANIMAL INTELLIGENCE.*

By JAs. WeIR, Jr., M.D. "INTELLIEFNCE is a conservative principle, and will
always direct effort and use into lines which will be
beneficial to its possessor." 4 This definition of intelligence is peculiarly applicable to the lower animals inasmuch as it does not convey any idea of a purely intellectual operation of the mind. Every instance of ratiocination in the lower animals has its origin in the
fundamental principle of benefit to the animal evincing
this this faculty of reason. The words reason and intelli-
gence are, in a measure, synonymous, for without gence are, in a measure, synonymous, for without
intelligence, reason cannot exist, and vice versa-without reason there can be no intelligence. They are both psychic factors, dependent each upon the other. ligence, yet high enough to lift the mental operation above the automatic and spontaneous action generally called instinct. Instinct itself is, in a certain sense, ations may not be due to reason. Instinct involves mental operations; if it did not, it would simply be reflex
action. It is heredity under a special name. The father transmits his mental peculiarities as well as his corporeal
individualities to his son. The experiences of thou individualities to his son. The experiences of thou-
sands of years leave their imprint on the succeeding sands of years leave their imprint on the succeeding
generations, until deductions and conclusions drawn from these experiences become in man that psyehic: a like experience and arrive, each in his own sphere and degree, at a kindred mental destination. by appropriate stimulation without mental cognizance. Instinct has always a mental element; and the lowest animal that lives is no more governed by reflex action her web is just as voluntary and is as much under mental direction and control as the action of a carpenanimal life give evidences of intelligence can no longe be denied. A very common rotifer whose body is cup shaped and whose tail is armed with forceps has been
seen to seize a larger specimen with its forceps, and thus swung itself violently about until it met a piately weed, this it seized with its forceps and began "the most extraordinary movements, which were obviously This it finally succeeded in doing, and the entire scen was so like intelligent action that the onserver con was so like intelligent action that the observer con-
cludes "so that if we were to depend upon appearances *From the American Namurnlist. me to attribute conscious determination to these the scale of animal life as the rhizopoda. Aethalia will
confine themselves to the water in a watch-glass in confine themselves to the water in a watch-glass in
which they are placed, but when the glass is placed on which they are placed, but when the glass is placed on
sawdust, they will leave the water and go to the dust to remain in water, as long as there is no sawdust in their vicinity, but as soon as they recognize the sawdust through the glass, they crawl over the rim of the latter
to get into a more pleasing abode. This is a wonderful example of conscious determination to be found in
an organism so low in the scale of life. Once, while exanining some fungal cells, Carter saw a still more noticed that one of the spore cells had ruptured and that grains of starch wore escaping from the crevice.
Suddenly an actinophrys came into the field of vision and proceding to the ruptured cell seized a grain of
starch and then retired to some distance. Presently it starch and then retired to some distance. Presently it through the crevice. "All this was repeated several
times, showing that the actinophrys knew that those were nutritious grains, that they were contained in
this cell, and that, although each time after incepting a grain it went away to some distance, it knew how to
find its way back to the cell again which furnished this nutriment." Oysters taken from a bank never
uncovered by the sea open their shells, lose the water uncovered by the sea open their shells, lose the water
within and soon die; but oysters kept in a reservoir and

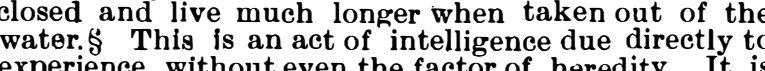
experience, without even the factor of heredity. It is
an instance of almost immediate adaptation to sur examples of animal intelligence in such a low order a the Helicida, yet several instances can be adduced

also have evinced love and affection,
A gentleman fixed a land snail, with the mouth of
the shell upward, in a chink of a rock. The animal protruded its foot to the utmost extent and. attaching it above, tried to pull the shell vertically in a straight
line. Then it stretched its body to the right side, its foot to the left side, pulled with all its strength and released the shell. There were intervals of rest
between these several attempts, during which. the snail remained quiescent. $\|$ Thus we see that it ex-
erted force in three directions, never twice in the same direction, which fact proves conscious determination and no slight degree of intelligence. An observer, M
Lonsdale, placed two snails in a small and badly kept

$$
\begin{aligned}
& \text { *Romanes: "Animal Intelligence," p. } 18 . \\
& \text { +H. J. Carter: "Annals of Natural History." }
\end{aligned}
$$

† I Ibid.
Dicquemase: Journal de Phyrique, vol. xxriii., p. 2 .

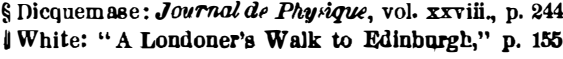
and ratiocination is found in animals as low down in occasionally left uncovered, learn to keep their shells garden. One of them was weak and poorly nourished, peared and was traced by its slimy track over a wall
peand peared and was
into a neighboring garden where there was plenty of
food. Mr. Lonsdale thought that it had deserted its ood. Mr. Lonsdale thought that it had deserted its comrade over the wall into the bountiful food supply sist its feeble companion when it lingered on the way. Here we see not only an example of menory and dis. crimination, but also of affection and solicitude. After the snail had made its voyage of discovery, with rare

unselfishness and true affection, it remembered its
sick mate and returned for it.
Beneath the pavement in front of $\mathrm{my}$ door a wasp (Vespa nigra) has her nest. The entrance to this nest s at the bottom of a sulcus formed by two paralle
bricks. I rolled a piece of paper into a compact wad and placed it between the bricks and over the entrance during her absence. When she returned she seized the paper with her jaws and forelegs and endeavored
to pull it away. This was prevented by the interpoto pull it away. This was prevented by the interpo-
sition of the brick on which she stood. She then went to the other side and tried again. Here she failed for the same reason. She then descended into the little gully between the bricks and easily removed the wad. When she again lett the nest, I replaced the paper. and on her return she went through the same per-
formance as at first. Again I replaced it, but the third time she went at once into the gully and re. moved the obstruction. This she did three times in dences of memory and ratiocination are too patent to be denied. Some nembers of another family, distantly related to the Helicida, the limpets, show evidences of
intelligence, inasmuch as they have a vers accurate intelligence, inasmuch as they have a vers accurate
memory of direction. Limpets, when at rest, live at memory of direction. Limpets, when at rest, live at to them as soon as they have satisfied their hunger. One very pointed instance of this homing sense is given by Hawkshaw, a most careful and exact obovered block of chalk. In the was a pedestal of flint which projected an inch or taken up its abode. The cleared space had several hollows where the animal could have easily sheltered after each of its excursions. $\dagger$
Not many years ago, a French exhibitor with a trained company of fleas passed through the country These insects had march, to dance, to feign death, to pull miniature
coaches, etc. While this does not evince voluntary ratiocination, it shows that fleas think and are capable
of receiving instruction. "When we consider the
habits of ants, their social relations, their large con!habits of ants, their social relations, their large conmunities, and elaborate habitations, their roadways, their possession of domestic animals, and even, in
some cases, of slaves, it nust be admitted that they
have a fair claim to rank next to man in the scale of intelligence." $\ddagger$

When Lubbock says that the ant ranks next to man uperior intelligence of the ant has been recognized and commented on by man since the very inception of history. The wisest man of his day King Solomon,
uses the ant to point a moral He considers her intelligence and industry worthy of emulation, and says to the sluggard: "Go to the ant, consider her ways and be wise." This one factor, intelligence, and the faculty of intercommunicating intelligently, makes tions make it a model republic. Ants are true socialists : communists of an ideal type. Theirs is a ion. The commonwealth is everything-individual weal is not considered. Man is susceptible to ind $\mathrm{i}$ vidual attachments which form the basis of his happiness. The affection of ants, on the contrary, is a "never distinguishing individuals, unless, as in the instance of the communal mother, connected with the doubtedly communicate. A short while ago I crushed a pismire in the track usually taken by the members of a colony iulubiting the hollow of a beech tree sently and, smelling the blood of his murdered companion, was seized with a panic terror, and rushed anto the nest. He shortly returned with thir noissance of the dead body and its surroundings. Then all of them examined the corpse, and, having satisfied themselves that their sister was dead, returned to the nest. In a few moments a large worker ant, accom-
panied by two soldier ants, came out, and, proceeding to the body, picked it up and carried it down the
tree to the ground. They then went beneath the grass and I lost sight of them. Their every action seemed to me to be governed by an almost human in -
telligence. The discoverer of the murder hurried into town, gave the alarm, and, quickly gathering some of his companions, went out in search of the murderer. On discovering that their companion was dead and
her slayer absent, they came back to town and sent ial party.

The ant is the only animal except man which has highly developed that they make a perfect success in rearing their cattle and in capturing their slaves. The herdsmen of these aphidian cattle can be seen patrolng the shrubs on which the aphides are grazing. On them out in the morning and carry them back at
night. They gather the eggs of the aphides, carry them into a specially built nursery, attend them care-
fully until the youne aphides are hatched out, and ully until the young aphides are hatched out, and
then carry them to the shrubs most liked by them for ood. Some strange sense enables then one another-an ant of the same species, but coming
from another nest, is immediately recogaized as a from another nest, is immediately reco † Hawk shaw : "Dournal Linn. Sac,, vol. xiv., p. 406. † Lubbock: : Ants, Bees, and W Wspe," p. 1.
5Kirby and Spence : Enlomology, "Perfect Society," 